\title{
CORNEAL TOPOGRAPHIC CHANGES AFTER EYELID PTOSIS SURGERIES MEASURED BY CORNEAL TOPOGRAPHY
}

\author{
By
Zakariya Abd El-Ghany Mohammed, Mohamed Amin Anwar El-Masry and Ehab Abd El-Samie El-Shiekh \\ Department of Ophthalmology, Faculty of Medicine, Al-Azhar University \\ Corresponding author: Zakariya Abd El-Ghany Mohammed, \\ Mobile: (+20)01065667623, E-mail: d.rzakariya1988@ gmail.com
}

\begin{abstract}
Background: The cornea is a complex structure which has a protective role, and responsible for about threequarters of the optical power of the eye. Pressure from the eyelids has been implicated in a range of shortand long-term corneal topographical changes.

Objective: To evaluate corneal topographic changes after eyelid ptosis surgeries measured by corneal topography by the Sirius system (CSO, Florence, Italy).

Patients and Methods: A total of 50 eyes of patients were enrolled in the study to be examined before and 6 weeks after ptosis surgeries using corneal topography device at Al-Azhar University Hospitals in the period extending from December 2018 to December 2019. A complete ophthalmological examination included uncorrected visual acuity, best corrected visual acuity, full slit lamp examination and evaluation of eyelid. Examination was done by the Sirius system to evaluate corneal topographic changes.

Results: Apical keratometry front $(\mathrm{AKF})$ was changed from $(44.63 \pm 1.34 \mathrm{D})$ to $(44.06 \pm 1.47 \mathrm{D})$ with statistically significant $(\mathrm{P}$ value $=0.002)$. Changes in central corneal thickness $(\mathrm{CCT})$, corneal astigmatism (CYL), average simulated keratometry (average K), and symmetry index front (SIF) obtained from Sirius were not statistically significant.

Conclusion: The pressure of upper eyelid in patients with ptosis appeared to inducing steepening of the superior cornea along this axis. The surgical correction of ptosis induces flattening of superior cornea as shown by significant decrease in AKF value postoperatively restoring corneal topography to a more regular state.
\end{abstract}

Keywords: Eyelid ptosis, corneal topography, corneal steepening.

\section{INTRODUCTION}

Ptosis is the drooping or sagging of an area of the body. Eyelid ptosis is an abnormally low position of the upper lid, which can affect one, or both of the eyelids can be divided into several categories but to simplify is broken down into two categories: congenital or acquired (Zoumalan and Lisman, 2010).
Corneal topography is a computer assisted diagnostic tool that creates a three-dimensional map of the surface curvature of the cornea. The greatest advantage of corneal topography is its ability to detect irregular conditions invisible to most conventional testing (Ruberti et al., 2011). 
Upper eyelid ptosis can cause refractive errors leading to amblyopia in childhood and persistently blurred vision in adult patients (Read et al., 2014).

Patients who have undergone upper eyelid surgery occasionally complain of blurred vision in the operated eye (Neimkin and Holds, 2016).

Corneal astigmatism is change by the pressure of the eyelids in the with the- rule direction, which results from flattening of the cornea by the eyelids (Maseedupally et al., 2015).

Surgical repositioning of the eyelid increased pressure vectors on the cornea and the globe from above, thereby inducing with-the-rule astigmatism (i.e., corneal curvature greatest at the 90-degree axis) (Byard et al., 2014).

Surgical procedures designed to correct ptosis should be directed toward correction of the underlying pathologic condition. The 3 categories of surgical procedures most commonly used in ptosis repair are external (trans-cutaneous) levator advancement, internal (transconjunctival) levator/tarsus/Müller muscle resection approaches and frontalis muscle suspensions (Cruz and Akaishi, 2018).

The present study aimed to evaluate corneal topographic changes after eyelid ptosis surgeries measured by corneal topography by the Sirius system (CSO, Florence, Italy).

\section{PATIENTS AND METHODS}

This is a prospective study that included 50 eyes of patients who underwent repair of blepharoptosis, at ophthalmology department of Al-Azhar university hospitals in the period extending from December 2018 to December 2019.

Inclusion criteria: Male and female patients with any degree of ptosis and age more than 4 years.

Exclusion criteria: Patients with any associated corneal or eye lid diseases and with repeated eye lid surgical procedures.

An informed written consent was taken from patients before history taking and investigation.

\section{All participants were subjected to:}

\section{History:}

A detailed history of present illness includes asking about the onset, duration, progression, and severity of the disease.

\section{Examination:}

Including visual acuity measurement using Landolt's broken ring chart,cyxloplegic refraction, evaluation of the best-corrected visual acuity, slit lamp biomicroscopy, palpebral fiisure hight, the upper eyelid margin reflex distance, levator function, Bell's phenomenon, pupil, and corneal sensation were also evaluated.

\section{Corneal topography:}

Before and 6 weeks after ptosis surgeries to determine the corneal topographic changes. All eyes were examined by the Sirius system (CSO, Florence, Italy).

All data were obtained using the computed topography system. Study parameters included average K, CYL, SIF, $\mathrm{AKF}$ and CCT.

These pre and postoperative data were compared and statistically analyzed. 
Statistical analysis:

Data were collected, revised, coded and entered to the Statistical Package for The Social Science program (Released 2011. IBM SPSS Statistics for Windows, Version 20.0. Armonk, New York: IBM Corp) the quantitative data were presented as mean, standard deviations and ranges while qualitative variables were presented as number and percentages. The comparison with quantitative data between two paired groups was done by using Paired t-test. The confidence interval was set to $95 \%$ and the margin of error accepted was set to 5\%. P-value was considered significant: $\mathrm{P}$-value $<0.05$ was considered significant.

\section{RESULTS}

This is a prospective study that included 50 eyes, 20 eyes of male patients
\&30 eyes of female patients with age ranged from (5-52years) (Table 1).

Table (1): Demographic characters of studied cases

\begin{tabular}{|l|c|c|}
\hline & No. & \% \\
\hline Sex & 20 & 40.0 \\
Male & 30 & 60.0 \\
Female & \multicolumn{2}{|c|}{$5-52$} \\
\hline Age (years) & \multicolumn{2}{|c|}{$20.70 \pm 15.68$} \\
Min. - Max. & \multicolumn{2}{|c|}{} \\
Mean + SD. &
\end{tabular}

Table (2): Criteria of ptosis in the studied patients

\begin{tabular}{|c|c|c|}
\hline Type & $\mathbf{N}$ & $\mathbf{\%}$ \\
\hline Congenital & $\mathbf{3 5}$ & $\mathbf{7 0 . 0}$ \\
\hline Acquired & $\mathbf{1 5}$ & $\mathbf{3 0 . 0}$ \\
\hline Total & $\mathbf{5 0}$ & $\mathbf{1 0 0}$ \\
\hline Degree & $\mathbf{N}$ & $\boldsymbol{\%}$ \\
\hline Mild & $\mathbf{9}$ & $\mathbf{1 8 . 0}$ \\
\hline Moderate & $\mathbf{2 3}$ & $\mathbf{4 6 . 0}$ \\
\hline Sever & $\mathbf{1 8}$ & $\mathbf{3 6 . 0}$ \\
\hline Total & $\mathbf{5 0}$ & $\mathbf{1 0 0}$ \\
\hline levator muscle function & $\mathrm{N}$ & $\%$ \\
\hline Poor & $\mathbf{2 0}$ & $\mathbf{4 0 . 0}$ \\
\hline Fair & $\mathbf{1 3}$ & $\mathbf{2 6 . 0}$ \\
\hline Good & $\mathbf{1 7}$ & $\mathbf{3 4 . 0}$ \\
\hline Total & $\mathbf{5 0}$ & $\mathbf{1 0 0}$ \\
\hline
\end{tabular}

Table (3): Distribution of studied cases according to type of operation

\begin{tabular}{|c|c|c|}
\hline Operation & N & \% \\
\hline Sling & 20 & 40.0 \\
\hline Levator resection & 30 & 60.0 \\
\hline Total & 50 & 100 \\
\hline
\end{tabular}


The post-operative value of AKF changed from $(44.63 \pm 1.34 \mathrm{D})$ to $(44.06 \pm$ 1.47D) with statistically significant $(\mathrm{P}$ value $=0.002$ ) with average dioptric change at 6 weeks after surgery $(0.57 \mathrm{D})$. However, change in CCT; CYL, average $\mathrm{K}$, and SIF obtained from Sirius were not statistically significant postoperatively at follow-up visit (Table 4).

Superior corneal steepening underneath the ptotic eyelid can be seen in all patients, and corneal topographic maps showed the difference after the surgical correction of ptosis. Tangential corneal topography shows red-orange islands corresponding to the areas of superior, corneal focal steepening and the modification after surgical ptosis repair. Postoperative topographic maps showed a flattening of the superior corneal steepening as compared with the preoperative state of the superior cornea, obtaining more regular corneal surface Figure (1) to Figure (12).

Table (4): Changes in AKF, SIF, CYL, CCT, and average K pre and post operative:

\begin{tabular}{|c|c|c|c|}
\hline & $\begin{array}{c}\begin{array}{c}\text { Before } \\
(\mathbf{n}=\mathbf{5 0})\end{array} \\
\end{array}$ & $\begin{array}{c}\text { After } \\
(\mathbf{n}=\mathbf{5 0})\end{array}$ & $\mathbf{P}$ \\
\hline \multicolumn{3}{|l|}{ AKF: } & \multirow{3}{*}{0.002} \\
\hline Min. - Max. & $42.12-47.51 \mathrm{D}$ & $41.31-46.12 \mathrm{D}$ & \\
\hline Mean \pm SD & $44.63 \pm 1.34 \mathrm{D}$ & $44.06 \pm 1.47 \mathrm{D}$ & \\
\hline \multicolumn{3}{|l|}{ SIF: } & \multirow{3}{*}{0.272} \\
\hline Min. - Max. & $-1.12-1.5$ & $-0.57-1.3$ & \\
\hline Mean \pm SD & $0.29 \pm 0.79$ & $0.19 \pm 0.50$ & \\
\hline \multicolumn{3}{|l|}{ CYL: } & \multirow{3}{*}{0.456} \\
\hline Min. - Max. & $-3.22--0.96 \mathrm{D}$ & $-3.56--0.69 \mathrm{D}$ & \\
\hline Mean \pm SD & $-1.66 \pm 0.72 \mathrm{D}$ & $-1.55 \pm 0.75 \mathrm{D}$ & \\
\hline \multicolumn{3}{|l|}{ CCT: } & \multirow{3}{*}{0.473} \\
\hline Min. - Max. & $522-593$ & $519-574$ & \\
\hline Mean \pm SD & $551.70 \pm 19.55$ & $552.64 \pm 17.80$ & \\
\hline \multicolumn{3}{|l|}{ average $K$ : } & \multirow{3}{*}{0.183} \\
\hline Min. - Max. & $40.89-44.22 \mathrm{D}$ & $40.57-44.50 \mathrm{D}$ & \\
\hline Mean \pm SD & $42.93 \pm 1.05 \mathrm{D}$ & $42.82 \pm 1.32 \mathrm{D}$ & \\
\hline
\end{tabular}

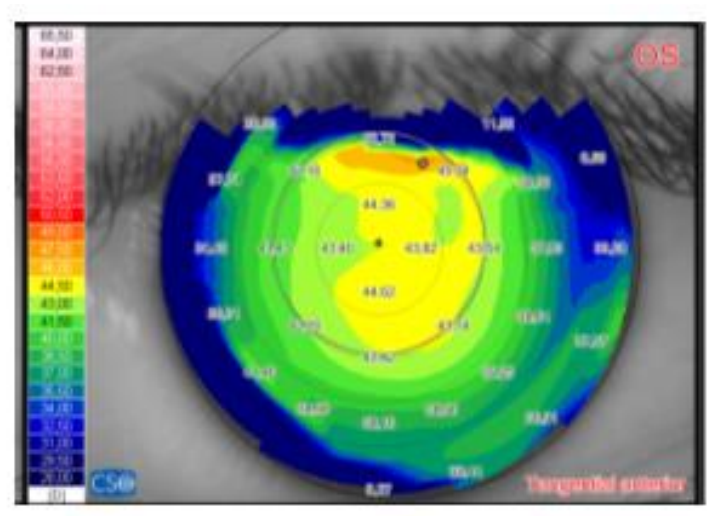

Figure (1): Preoperative comeal topography of Case (1)

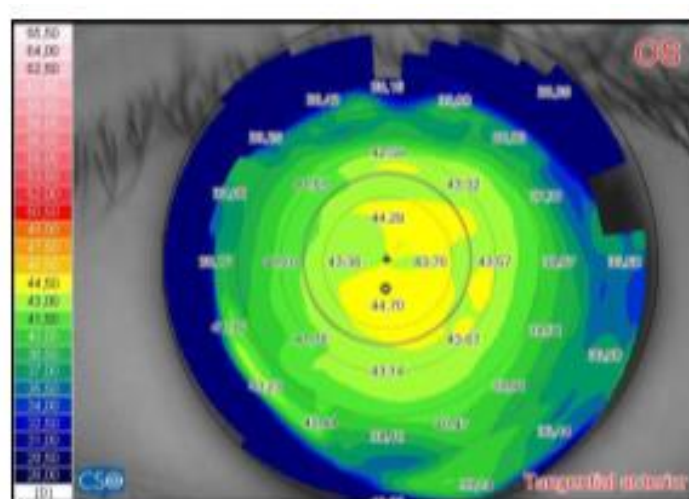

Figure (2): Six weeks Postoperative corneal topography of Case (1) 


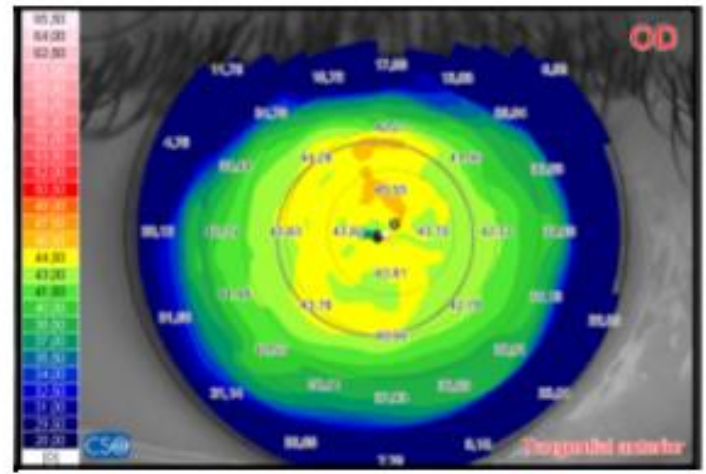

Figure (3): Preoperative corneal topography of Case (2)

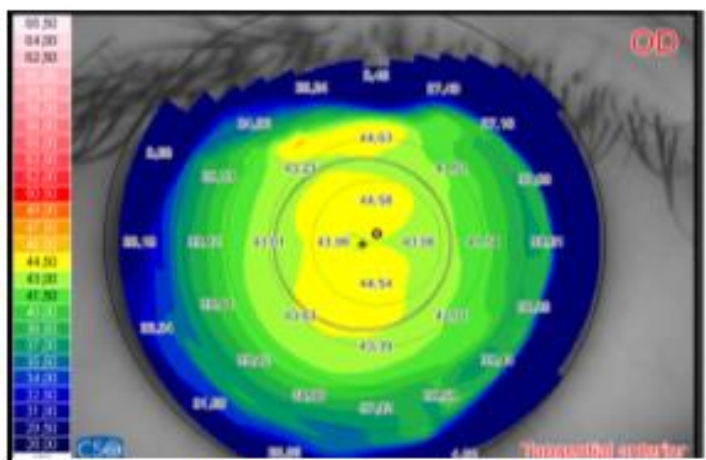

Figure (5): Preoperative corneal topography of Case (3)

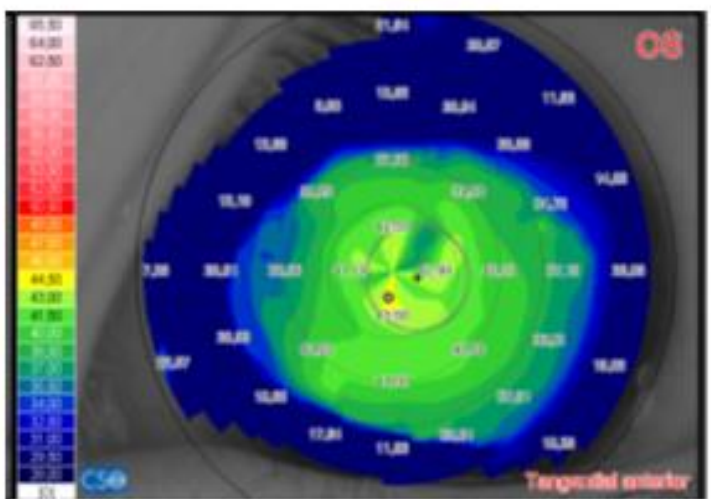

Figure (7): Preoperative corneal topography of Case (4)

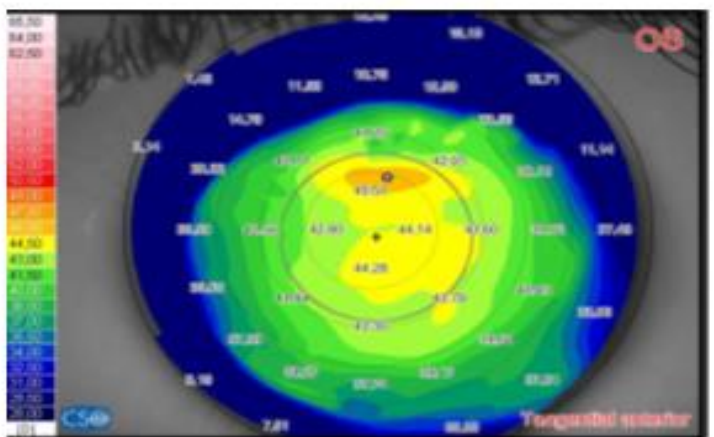

Figure (9): Preoperative corneal topography of Case (5)

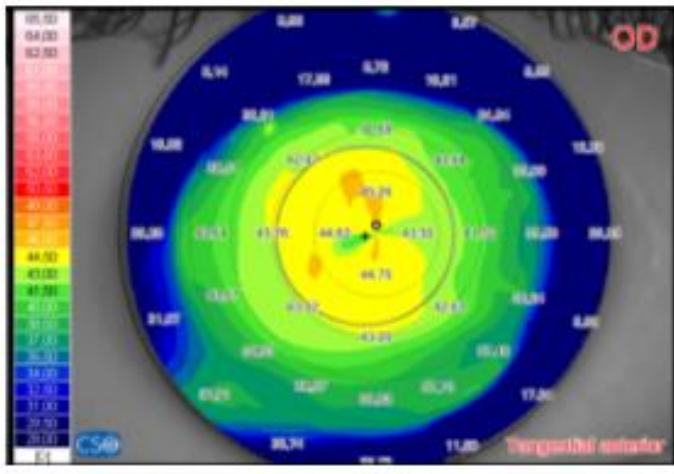

Figure (4): Six weeks Postoperative corneal topography of Case (2)

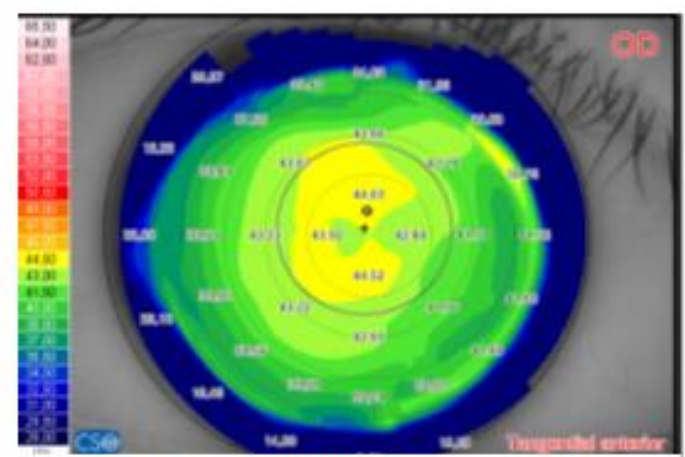

Figure (6): Six weeks Postoperative corneal topography of Case (3)

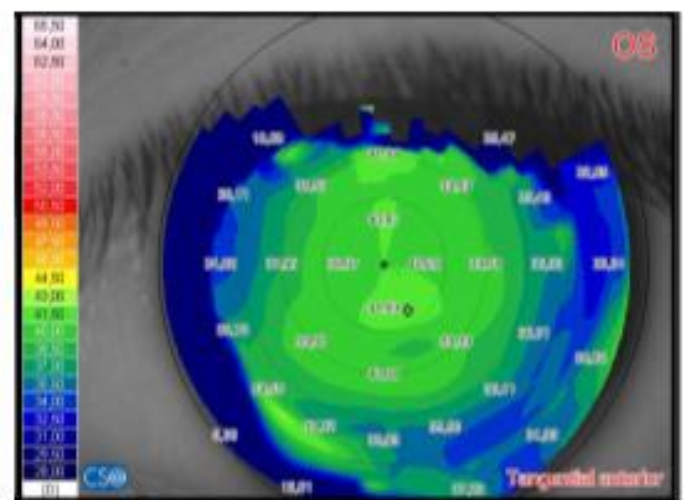

Figure (8): Six weeks Postoperative corneal topography of Case (4)

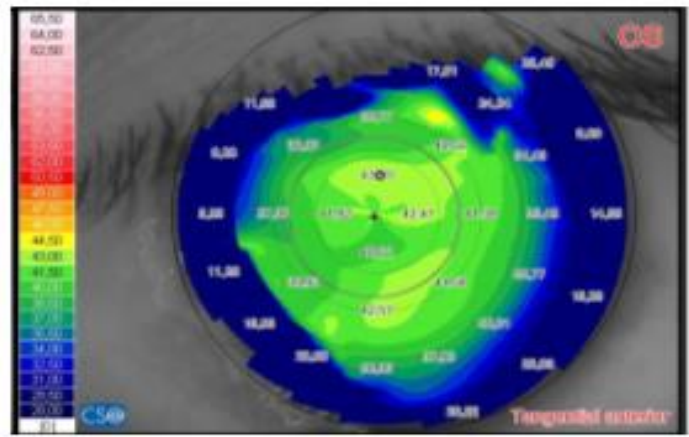

Figure (10): Six weeks Postoperative corneal topography of Case (5) 


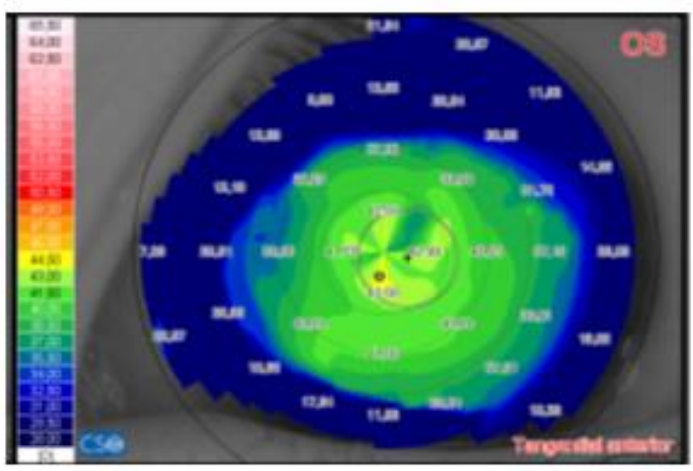

Figure (11): Preoperative corneal topography of Case (6)

\section{DISCUSSION}

In patients affected by eyelid ptosis, normal corneal curvature and symmetry between the 2 eyes are lost (Savino et al., 2016).

Karabulut and Fazil, (2019) reported no statistical change in refractive error, keratometry, and toricity after surgery in patients with acquired ptosis and direction of the axis remained relatively stable in their study.

Agrawal and Ravani (2016) Found an average decrease of $(0.18$ D) in astigmatism following congenital ptosis surgery, which was not found statistically significant.

All of the above studies used refractive power evaluation or keratometry to analyze the corneal curvature changes. However, analyzing the cornea with keratometry gives information about a limited central cornea without measuring periphery. So we analyzed the corneal curvature changes with topography before and after ptosis surgery to assess the effects of eyelid position and scar induced by surgery.

In this study, we used Sirius that measures both anterior and posterior

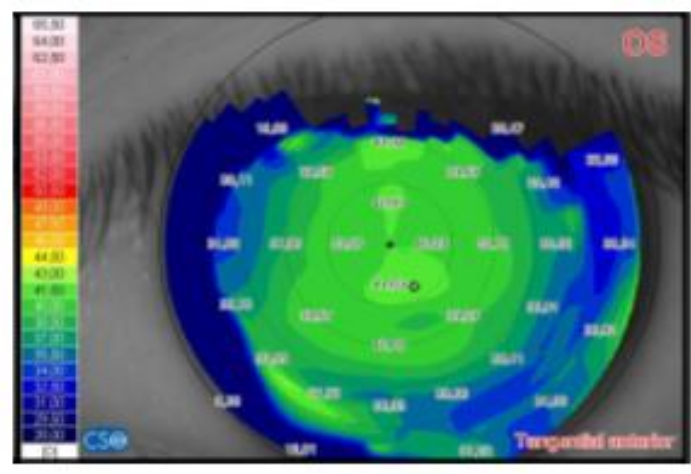

Figure (12): Six weeks Postoperative corneal topography of Case (6)

corneal surface by combining Scheimpflug tomography and Placido disc topography. This device gives information about the (average K), (CYL), (SIF), $(\mathrm{AKF})$, and (CCT) over a diameter of 12 $\mathrm{mm}$.

In the present study the post-operative value of AKF was changed from (44.63 \pm $1.34 \mathrm{D})$ to $(44.06 \pm 1.47 \mathrm{D})$ with statistically significant $(\mathrm{P}$ value $=0.002)$ with average dioptric change at 6 weeks after surgery $(0.57 \mathrm{D})$.

However, change in CCT, CYL, average $\mathrm{K}$, and SIF obtained from Sirius were not statistically significant postoperatively at follow-up visit in this study.

The present study nearly matched with the study done by Savino et al. (2016). In their study after surgical ptosis repair, corneal topography demonstrated a reduction in average $\mathrm{K}$ of $(0.15 \pm 0.47 \mathrm{D})$ and in CYL of $(0.26 \pm 1.12 \mathrm{D})$. Significant differences were found in AKF (21.84 \pm 1.76 D). CCT did not show significant differences between preoperative and postoperative examinations. Postoperative topographic maps showed a reduction of symmetry index front $(0.10 \pm 0.64 \mathrm{D})$. 
AKF showed a significant decrease after 6 weeks, indicating more regular cornea is obtained with time. Regression of AKF might correlate with resolution of early postoperative edema and might indicate flattening of cornea to a more regular state in the late postoperative period similar to the study of Karabulut and Fazil (2019) Savino et al. (2016) also noted statistically significant postoperative reduction in $\mathrm{AKF}$ and postulated that superior corneal steepening under the ptotic eyelid showed flattening of superior cornea and more regular surface after ptosis surgery without change in corneal thickness with aid of Sirius system.

This study suggests that modifications in eyelid position induce pressure on the anterior corneal surface, modifying corneal surface and leading to topographic changes that may affect the quality of vision.

\section{CONCLUSION}

The surgical correction of ptosis induces flattening of superior cornea as shown by significant decrease in AKF value postoperatively and restores corneal topography to a more regular state. An indicated ptosis surgery, is recommended to be done first prior to an intended cataract or refractive surgery to avoid refractive surprises.

\section{REFERENCES}

1. AGRAWAL, G. and RAVANI, S. (2016): Astigmatic changes following ptosis correction surgery in 30 consecutive children seen in a regional institute of ophthalmology.
International Journal of Current Research and Review, 8, 1.

2. BYARD, S. D., SOOD, V. and JONES, C. A. (2014): Long-term refractive changes in children following ptosis surgery: a case series and a review of the literature. International Ophthalmology, 34, 1303-1307.

3. CRUZ, A. A. V. and AKAISHI, A. (2018): Frontalis-Orbicularis Muscle Advancement for Correction of Upper Eyelid Ptosis: A Systematic Literature Review. Ophthalmic Plast Reconstr Surg, 34, 510-515.

4. KARABULUT, G. O. and FAZIL, K. (2019): Corneal Topographical Changes after Müller's Muscle-conjunctival Resection Surgery. Ophthalmic Plastic \& Reconstructive Surgery, 35, 177-181.

5. MASEEDUPALLY, V., GIFFORD, P. and SWARBRICK, H. (2015): Variation in normal corneal shape and the influence of eyelid morphometry. Optometry and Vision Science, 92, 286-300.

6. NEIMKIN, M. G. and HOLDS, J. B. (2016): Evaluation of eyelid function and aesthetics. Facial Plastic Surgery Clinics, 24, 97-106.

7. READ, S. A., VINCENT, S. J. and COLLINS, M. J. (2014): The visual and functional impacts of astigmatism and its clinical management. Ophthalmic and Physiological Optics, 34, 267-294.

8. RUBERTI, J. W., SINHA ROY, A. and ROBERTS, C. J. (2011): Corneal biomechanics and biomaterials. Annual review of biomedical engineering, 13, 269-295.

9. SAVINO, G., BATTENDIERI, R., RISO, M., TRAINA, S., POSCIA, A., D'AMICO, G. and CAPOROSSI, A. (2016): Corneal topographic changes after eyelid ptosis surgery. Cornea, 35, 501-505.

10.ZOUMALAN, C. I. and LISMAN, R. D. (2010): Evaluation and management of unilateral ptosis and avoiding contralateral ptosis. Aesthetic surgery journal, 30, 320-328. 


\section{التغير ات التي تحدث في تضاريس القرنية بعد جر احات تدلي الجفن عن طريق قياس تصوير سطح القرنية}

زكريا عبدالغني محمد، محمد أمين أنور المصرى، إيهاب عبدالسميع الشيخ

قسم طب وجراحة العيون, كلية الطب، جامعةالأزهر

E-mail: d.rzakariya1988@gmail.com

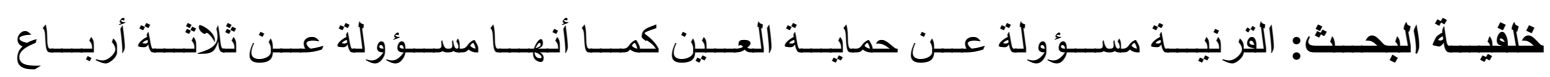

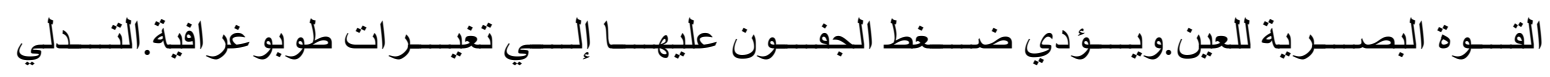

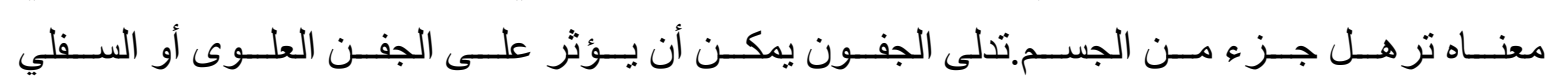

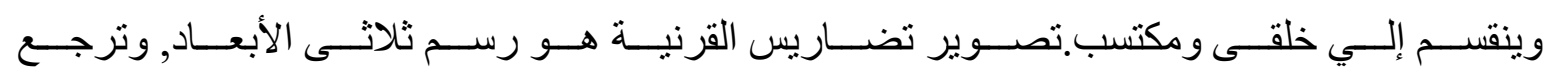

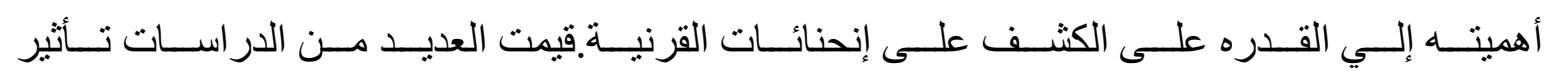

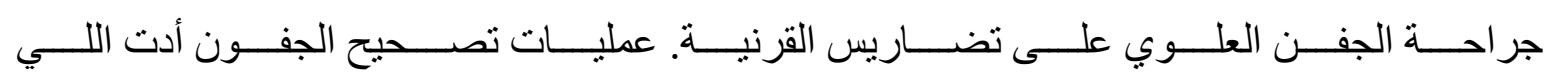
تغيرات إنكساريه في القرنية.

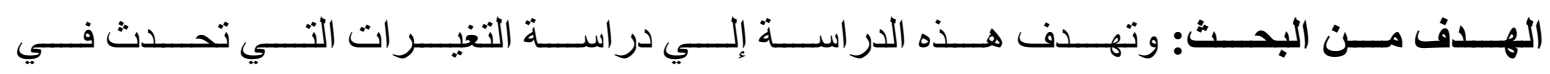
تضاريس القرنية بعد جر احات تدلى الجفن العلوي.

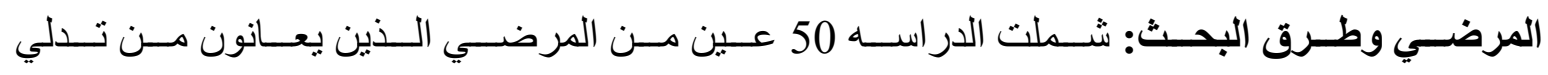

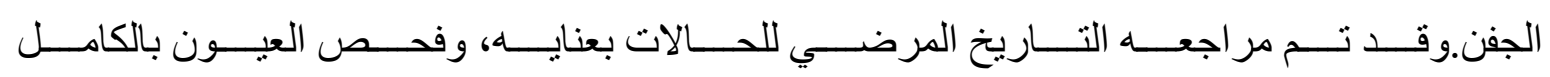
و التصوير الطوبوغري قبل الجر احه، وبعد 6 أسابيع من إجراء العملية.

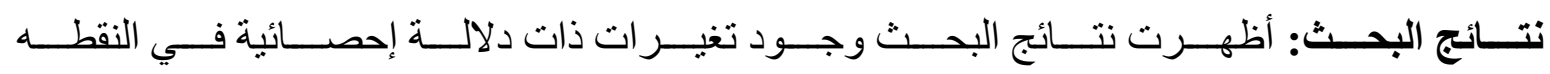

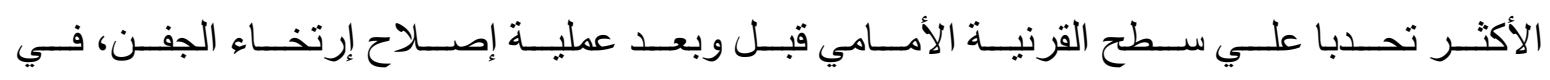

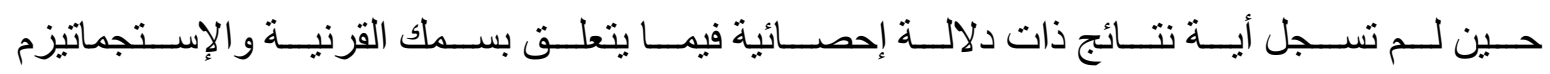
وعدم التناسق السطحي للقرنية و القوة الإنكسارية للقرنية.

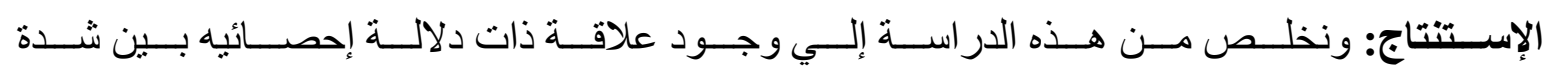

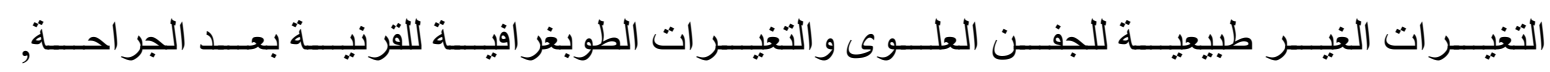

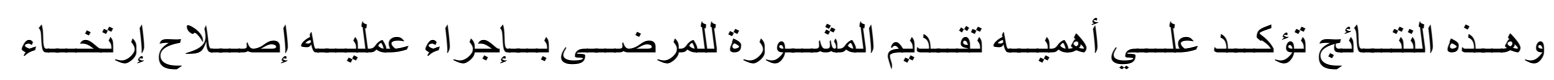
الجفن العلوى وخاصة فى الأطفال.

الكلمات الدالة: تدلي الجفن، تضاريس القرنية، تصوير سطح القرنبة. 